\title{
Gerald Taylor (1933-2020)
}

\author{
Juan Carlos Estenssoro
}

\section{OpenEdition}

Journals

Édition électronique

URL : https://journals.openedition.org/jsa/18202

DOI : $10.4000 /$ jsa. 18202

ISSN : 1957-7842

\section{Éditeur}

Société des américanistes

\section{Édition imprimée}

Date de publication : 30 juin 2020

Pagination : 251-253

ISBN : 978-2-902715-13-8

ISSN : 0037-9174

\section{Référence électronique}

Juan Carlos Estenssoro, " Gerald Taylor (1933-2020) », Journal de la Société des américanistes [En ligne], 106-1 | 2020, mis en ligne le 30 juin 2020, consulté le 26 septembre 2022. URL : http:// journals.openedition.org/jsa/18202 ; DOI : https://doi.org/10.4000/jsa.18202 


\title{
Gerald Taylor (1933-2020)
}

\author{
Juan Carlos EstensSORO *
}

Paris, 2 avril 2020

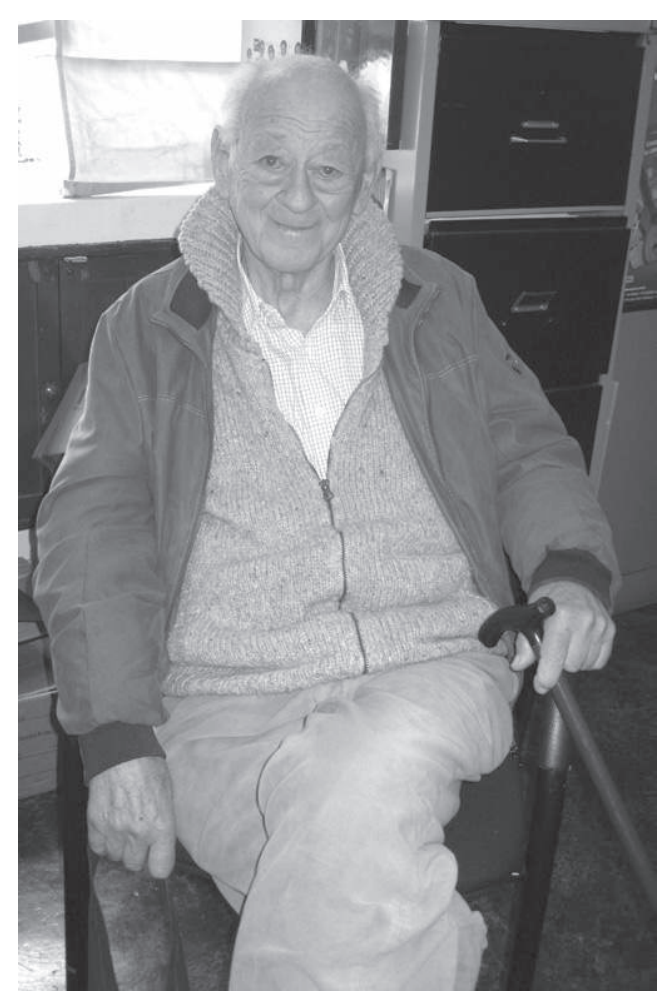

Fig. 1 - Gerald Taylor à Lima, 2014

(photo K. Pacheco, IFEA).

* Centre de recherche sur l'Amérique espagnole coloniale (CRAEC), université Sorbonne nouvelle-Paris 3 [jcestenssoro@yahoo.es].

Journal de la Société des américanistes, 2020, 106-1, p. 251-253. (C) Société des américanistes. 
Sans médailles, ni chaire à l'université, à l'EHESS ou au Collège de France, sans publications dans des revues indexées, ni de livres publiés à des milliers d'exemplaires par des maisons d'éditions célèbres, même pas promu directeur de recherches par le CNRS, Gerald Taylor (Melbourne, 13/09/1933 - Paris, 01/04/2020) vient de nous quitter. Comme tant d'autres personnes fragiles et vulnérables, il a succombé suite à une contamination au coronavirus, certainement attrapé dans des établissements de santé qu'il était obligé de continuer à fréquenter régulièrement sans avoir pu jouir du privilège de se protéger grâce au confinement. Sans des soins quotidiens, il aurait mis irrémédiablement sa vie en péril; l'accès à ces soins lui a coûté la vie.

Avec un CV sans honneurs particuliers en France, on pourrait se demander à quoi bon déranger les lecteurs quand un déferlement de morts de célébrités pointe à l'horizon de ces tragiques semaines comme une danse macabre. Sans honneurs... et pourtant. Gerald Taylor (qui sans doute aurait été jugé très sévèrement de nos jours par une visite HCERES) incarne plusieurs des mérites de ce qui fut un certain modèle, avec ses vertus et ses défauts, de la recherche à la française. Gerald Taylor, qui défendait toujours farouchement l'autonomie de la recherche et des chercheurs comme des producteurs de savoir ayant besoin d'une liberté équivalente à celle des artistes créateurs, n'aurait probablement pas pu développer ses recherches ni les diffuser ailleurs que dans le pays qui l'accueillit. Peu connu et pas reconnu en France, les ouvrages de Gerald Taylor sont néanmoins, pour ne donner qu'un indice, depuis au moins une décennie, les meilleures ventes de l'Institut français d'études andines (IFEA) ${ }^{1}$, dont les publications sont constamment épuisées et rééditées dans des domaines spécialisés où, très souvent, les stocks très modestes ne trouvent leur public et leurs acheteurs qu'au compte-gouttes. Avec sa bonhomie et son air modeste, toujours accessible à tous, Gerald Taylor était un des plus importants (sinon le plus important) spécialistes des Andes en France et, sans aucun doute, le premier véritable philologue de la langue quechua avec lequel put compter le réseau scientifique français.

La production de Gerald Taylor est diverse, à l'image de ses amples intérêts. Après une première orientation vers l'histoire de l'art qui le conduisit de son Australie natale en Italie, il s'installa à Paris au début des années 1960 pour étudier le javanais classique avant de découvrir l'Amérique latine. Ses travaux se concentreront sur deux langues: le quechua et le nheengatu (lingua geral du Brésil), et seront tout particulièrement consacrés à la dialectologie et à la tradition orale. Il milita aussi avec générosité pour que les langues autochtones

1. L'ouvrage Rites et traditions de Huarochirí: manuscrit quechua du début du $17^{e}$ siècle a été réédité une vingtaine de fois entre 1980 et 1995, le plus souvent dans des versions revues et augmentées, et traduit en plusieurs langues, à commencer bien sûr par l'espagnol (Taylor 1987). 
retrouvent une place digne dans les sociétés actuelles, promouvant l'éducation bilingue, principalement au Pérou. Mais l'œuvre la plus importante de Taylor est sans doute son travail autour du Manuscrit de Huarochirí (vers 1610). Ce texte quechua, racontant l'histoire et les sagas des divinités de cette région des Andes centrales, est une somme de la mythologie des Andes et un des monuments de la littérature mondiale au même titre que le Chilam Balam, le Livre des morts égyptien, l'Épopée de Gilgamesh, la Théogonie ou le Mahâbhârata. Gerald Taylor lui consacra sa vie, non seulement fixant le texte grâce à une transcription paléographique soignée mais faisant émerger pour la toute première fois l'éclat de son sens le plus authentique, grâce à des traductions successives en français et en espagnol qu'il ne cessa de retoucher et d'affiner avec un soin scrupuleux. Ce travail, accompagné de certains de ses articles majeurs ${ }^{2}$, font de Gerald Taylor le fondateur de la nouvelle philologie dans les Andes. C'est grâce à ces publications que sont devenus possibles d'innombrables autres travaux d'historiens, de linguistes, d'anthropologues, d'archéologues et de spécialistes de littérature. Nous lui en sommes tous redevables.

Gerald Taylor, en outre, était un phénomène de par sa capacité à s'intéresser aux autres et à s'adresser à tous. Personne ne sait combien de langues il maîtrisait (au moins une quarantaine), ni en combien de langues et dialectes il était capable de communiquer. Toujours avec une nouvelle grammaire à la main, il explorait un nouvel univers. À l'hôpital, avant de nous quitter, il parlait en turc à une des aides-soignantes, s'adressant à elle dans sa langue maternelle pour pouvoir ainsi la remercier de son dévouement et de sa gentillesse. Sa dernière pensée fut pour ses amis et leur état de santé.

Travaillant jusqu'à la dernière minute, plusieurs de ses travaux attendent une prochaine publication.

\section{Références citées}

TAYLOR Gerald

1974 «Camay, Camac et Camasca dans le manuscrit quechua de Huarochiri », Journal de la Société des américanistes, 63, p. 231-244, https://www.persee. fr/doc/jsa_0037-9174_1974_num_63_1_2128, consulté le 10/06/2020.

1980 «Supay », Amerindia, 5, p. 47-63. https://www.vjf.cnrs.fr/sedyl/amerindia/ articles/pdf/A_05_03.pdf, consulté le 10/06/2020.

1987 Ritos y tradiciones de Huarochirí del siglo XVII, Instituto de Estudios Peruanos/ Institut français d'études andines, Lima.

2. «Camac, camay et camasca» (Taylor 1974) et « Supay » (Taylor 1980), pour ne mentionner que deux publications en français disponibles sur internet, consacrés, l'un à rétablir le sens des rapports entre les hommes et les dieux à l'époque préhispanique, l'autre à comprendre les mécanismes de traduction et de transformation religieuse coloniale. 
